\title{
Puberte Dönemindeki Kız Mücadele Sporcularının Antropometrik Ölçümlerinin ve Somatotip Yapılarının İncelenmesi
}

\author{
Vedat AYAN' ${ }^{1}$, Selami YÜKSEK ${ }^{1} \mathbb{D}$, Fatih GÜR ${ }^{2 *}$, Burak KURAL ${ }^{1}$, Yasin \\ DEMIRCAN ${ }^{1}$ (ID
}

\author{
${ }^{1}$ Trabzon Üniversitesi, Spor Bilimleri Fakültesi. \\ ${ }^{2}$ Pamukkale Üniversitesi, Spor Bilimleri Fakültesi.
}

Orijinal Makale

Gönderi Tarihi: 09.08.2021
Kabul Tarihi: 25.12.2021
DOI:10.30769/usbd.980719

Online Yayın Tarihi: 31.12.2021

\section{$\ddot{O} \mathbf{z}$}

$\mathrm{Bu}$ araştırma, taekwondo, judo ve karate branşlarındaki kız sporcuların antropometrik ölçüm değişkenleri ile somatotip bileşenlerini saptamak ve aynı zamanda puberte döneminde bu spor branşları arasındaki antropometrik ölçüm ve somatotip yap1 bakımından ne gibi farklılıklar olduğunu ortaya koymak amacıyla yapıldı. Araştırmada tanımlayıcı araştırma kapsamına giren alan tarama yöntemi kullanıldı. Araştırmanın örneklemini, Trabzon ilinde yaşayan ve mücadele sporlarında lisanslı olan toplam $41 \mathrm{k} 1 \mathrm{z}$ sporcu (taekwondo $n=16$, judo $n=16$ ve karate $n=9$ ) oluşturdu. Araştırma kapsamında sporcuların antropometrik ölçümleri Anthropometric Standardization Reference Manual (ASRM) ve International Biological Programme'1n (IBP) öngördüğü teknikler doğrultusunda gerçekleştirildi. Araştırmaya katılan sporcularının boy uzunluğu, vücut ağırlığı, deri kıvrım kalınlığı (dkk), genişlik ve çevre ölçümleri alındı. Sporcuların somatotip özelliklerini belirlemek amacıyla Heath-Carter yöntemi kullanıldı. Elde edilen verilerin istatistiksel analizi SPSS 23.0 paket programı aracılığıyla gerçekleştirildi. Bütün istatistiksel yöntemler için alfa $(\alpha)$ anlamlılık düzeyi 0,05 olarak kabul edildi. Kız sporculardan elde edilen antropometrik ölçümler incelendiğinde, deri kıvrım kalınlığı (triceps, subscapular, suprailiac, calf), genişlik (dirsek, diz) ve çevre (biceps, calf) ölçümleri açısından gruplar arasında istatiksel olarak anlamlı bir fark görülmedi ( $\mathrm{p}>0.05)$. Kız sporcuların branşlara göre somatotip ortalama değerleri taekwondo 4-43 (mezomorf endomorf), judo 3-4-3 (dengeli mezomorf) ve karate 4-4-3 (mezomorf endomorf) olarak bulundu. Kiz sporcuların somatotip yapıları açısından gruplar arasında istatiksel olarak anlamlı bir fark görülmedi $(\mathrm{p}>0.05)$. Sonuç olarak puberte dönemindeki kız taekwondo, judo ve karate sporcularının antropometrik ölçümleri ve somatotip yapıları belirlendi. Elde edilen verilerin erken dönem sporcu seçimine ve bu alanda gerçekleştirilen çalışmalara katkı sağlayacağı düşünülmektedir.

Anahtar kelimeler: Antropometri, judo, karate, somatotip, taekwondo

\section{Investigation of Anthropometric Measurements and Somatotype Structures of Female Fighting Athletes in Puberty Period}

\begin{abstract}
This research was carried out to determine the anthropometric measurement variables and somatotype components of female athletes in taekwondo, judo and karate branches, and also to reveal the differences between these sports branches in terms of anthropometric measurement and somatotype structure during puberty. In the study, the field survey method, which is within the scope of descriptive research, was used. The sample of the study consisted of 41 female athletes (taekwondo $n=16$, judo $n=16$ and karate $n=9$ ) living in Trabzon and licensed in combat sports. Within the scope of the research, the anthropometric measurements of the athletes were carried out in accordance with the techniques prescribed by the Anthropometric Standardization Reference Manual (ASRM) and the International Biological Program (IBP). Height, body weight, skinfold thickness (DKK), width and circumference measurements of the athletes participating in the study were taken. Heath-Carter method was used to determine the somatotype characteristics of the athletes. Statistical analysis of the obtained data was carried out using the SPSS 23.0 package program. The alpha $(\alpha)$ significance level was accepted as 0.05 for all statistical methods. When anthropometric measurements obtained from female athletes were examined, there was no statistically significant difference between the groups in terms of skinfold thickness (triceps, subscapular, suprailiac, calf), width (elbow, knee) and circumference (biceps, calf) measurements $(p>0.05)$. Somatotype average values of female athletes according to branches were found as taekwondo 4-4-3 (mesomorph endomorph), judo 3-4-3 (balanced mesomorph) and karate 4-4-3 (mesomorph endomorph). There was no statistically significant difference between the groups in terms of somatotype structures of female athletes $(p>0.05)$. There was no statistically significant difference between the groups in terms of somatotype structures of female athletes ( $\mathrm{p}>0.05)$. As a result, anthropometric measurements and somatotype structures of pubertal female taekwondo, judo and karate athletes were determined. It is thought that the data obtained will contribute to the selection of early athletes and the studies carried out in this field.
\end{abstract}

Keywords: Anthropometry, Judo, Karate, Somatotype, Taekwondo

*Sorumlu Yazar: Fatih GÜR, E-posta: fatih-gur@hotmail.com 


\section{GíRIŞ}

Vücut yapısı ve sportif performans ilişkisi spor bilimleri alanındaki araştırma konularının odak noktalarından biri olarak kabul edilmektedir. Herhangi bir spor branşında başarılı olmayı etkileyen faktörler arasında söz konusu branşa uygun vücut yapısına sahip olmak da gösterilmektedir. Atletizm branşında kısa ve uzun mesafe koşu sporcularının vücut yapıları arasındaki farklar veya uzun boylu olmanın bazı branşlarda sağladığı avantajlar bu duruma örnek olarak gösterilebilir. Basit trigonometri hesabı ile teniste servisin $1 \mathrm{~cm}$ daha yüksekten atılması, sporcuya rakibin servis kutusunda topu yerleştirebileceği ekstra $4 \mathrm{~cm} 2$ 'lik fazladan bir alan sağlamaktadır (Maughan, 2009). Bu sebeple spor bilimleri alanındaki uzmanlar, sporcuların fizyolojik özelliklerinin yanı sıra, vücut kompozisyonları ve fiziksel özelliklerinin de sportif performans üzerindeki etkilerini araştırmaktadır (Ackland vd., 2012).

Sporcuların yapısal özelliklerini belirlemek için kullanılan yöntemler arasında antropometrik ölçümler ve somatotip yapının belirlenmesi yer almaktadır. Spor bilimleri alanında "International Society for the Advancement of Kinanthropometry (ISAK)" tarafindan standartlaştırılmış ve uluslararası düzeyde yaygın olarak kullanılan antropometrik ölçüm yöntemleri aracılığı ile sporcuların deri kıvrım kalınlıkları, ekstremite uzunlukları, çap ve çevre ölçümleri gerçekleştirilmekte (Silva ve Vieira, 2020) ve bu veriler üzerinden somatotip yapıları belirlenebilmektedir (Carter ve Heath, 1990). Bu ölçümler aracılığı ile belirli spor branşlarında başarı ihtimali arttıran yapısal özellikler belirlenebilmektedir (Olds, 2009). Bununla birlikte antropometrik ölçümler ve somatotip yapının belirlenmesi sporda erken yaşta yetenek seçimi ve yönlendirme çalışmalarında dikkate alınan bir özelliktir (Hume ve Stewart, 2018).

Puberte dönemi insan gelişim süreçleri içerisinde önemli değişimlerin yaşandı bir dönemdir. $\mathrm{Bu}$ dönemde gerçekleşen endokrin değişimler beraberinde cinsiyete özgü anlamlı fiziksel ve yapısal değişimleri getirir (Susman ve Rogol, 2004). Puberte dönemi ve sportif performans karşılıklı olarak etkileşim halinde olan iki olgudur. Bazı araştırmalar sporun artan enerji harcanması ve diğer etkileri sebebi ile puberte dönemi üzerindeki etkilerini incelemişlerdir (Habelt, Hasler, Steinbrück ve Majewski, 2011; Roemmich, Richmond ve Rogol, 2001). Diğer taraftan puberte döneminde aktif olarak gerçekleşen vücut yapısındaki değişim sporda yetenek seçimi, yönlendirme ve performans değerlendirmesi süreçleri üzerinde etkili rol oynamaktadır. $\mathrm{Bu}$ dönem boyunca gerçekleşen boy uzunluğu, vücut ağırlığı, kas ve yağ kütlesindeki ani değişimler sporcuların performanslarını ve ölçüm sonuçlarını etkileyebilmektedir (Hume ve Stewart, 2018). Dolayısı ile bu dönem içerisindeki sporcuların branşlara göre antropometrik ölçüm değerlerinin bilinmesi ve performanslarının puberte dönemindeki değişimlerin göz önüne alınarak değerlendirilmesi önem kazanmaktadır.

$\mathrm{Bu}$ araştırma Trabzon ilinde puberte dönemindeki lisanslı taekwondo, judo ve karate sporcularının antropometrik ölçüm değişkenleri ve somatotip bileşenlerini saptamak ve aynı zamanda bu spor branşları arasındaki antropometrik ölçüm ve somatotip yapı bakımından ne gibi farklılıkların olduğunu ortaya koymak amacıyla yapılmıştır. 
Ayan, V., Yüksek, S., Gür, F., Kural, B., \& Demircan, Y. (2021). Puberte Dönemindeki Kız Mücadele Sporcularının Antropometrik Ölçümlerinin ve Somatotip Yapılarının İncelenmesi. Ulusal Spor Bilimleri Dergisi, 5(2), 138-145.

\section{YÖNTEM}

\section{Araştırma Modeli}

Araştırmada tanımlayıcı araştırma yöntemlerinden biri olan alan tarama yöntemi kullanılarak gerçekleştirilmiş olup, örneklem grubunun belirlenmesinde seçkisiz olmayan örnekleme metotlarından biri olan uygun örnekleme metodu kullanılmıştır (Gürbüz ve Şahin, 2014).

\section{Çalışma Grubu}

Araştırma grubunu Trabzon ilinde lisanslı olarak taekwondo $(n=16)$, judo $(n=16)$ ve karate $(\mathrm{n}=9)$ branşlarında müsabık, yaş ortalamaları 12 olan toplam $41 \mathrm{kız}$ sporcu oluşturmaktadır. Araştırma öncesinde sporculardan ve velilerinden gerekli izinler alınmış ve araştırmaya katılım gönüllülük esasına dayalı olarak gerçekleştirilmiş̧tir.

\section{Veri Toplama Araci}

Araştırmaya katılan sporculardan alınan antropometrik ölçümler "International Biological Programme (IBP)" ve "International Society for the Advancement of Kinanthropometry" nin (ISAK) öngördüğü teknikler doğrultusunda gerçekleştirilmiştir (Marfell-Jones, Olds, Stewart ve Carter, 2006; Silva ve Vieira, 2020).

Sporcuların boy uzunluğu ve vücut ağırlığı ölçümleri gerçekleştirilmiştir. Deri kıvrım kalınlığı ölçümleri triceps, suprailiac, subscapular ve calf bölgelerinden, genişlik ölçümleri dirsek ve diz bölgelerinden, çevre ölçümleri ise üst kol ve baldır bölgelerinden alınmıştır. Sporcuların somatotip özelliklerini belirlemek için Heath-Carter yöntemi kullanılmıştır (Carter vd., 1990)

\section{Heath-Carter Somatotip Formülü}

Endomorfi $=-0.7182+0.1451 * \mathrm{x}-0.00068 * \mathrm{x} 2+0.0000014 * \mathrm{x} 3$

( $\mathrm{x}=$ "triceps" dkk + "suprailiac" dkk + "subscapula" dkk)

Boy Düzeltme Formülü $=\mathrm{x} * 170.18$ / boy $(\mathrm{cm})$

Mezomorfi $=[0.858+0.601 *$ dirsek genişliği - "bicondylar humerus" $(\mathrm{cm})+0.601 * \operatorname{diz}$ genişliği - "bicondylar femur" $(\mathrm{cm})+0.188$ * kol çevresi $(\mathrm{cm})+0.161$ * baldır çevresi $(\mathrm{cm})]-$ $[$ boy $(\mathrm{m}) * 0.131]+4.50$

Ektomorfi $=($ Boy uzunluğu-ağırlık oranı $) * 0.732-28.58$

(Boy-ağırlık oranı $=$ Boy $/ 3 \sqrt{ }$ Ağırlık)

Somatokartta $\mathrm{X}$ ve $\mathrm{Y}$ koordinatları yerleştirilirken aşağıdaki formüle göre hesaplanır.

$\mathrm{X}=$ Ektomorfi - Endomorfi

$\mathrm{Y}=2 \mathrm{x}$ Mezomorfi - (Endomorfi + Ektomorfi)

Bulunan X ve Y koordinatları somatokartta işaretlenerek somatotip belirlenir (Carter vd. 1990).

\section{Verilerin Analizi}

Araştırma bulgularının istatistiksel analizi için SPSS 23.0 paket programı kullanıldı. Verilerin normallik dağılımı Shapiro-Wilk testi ve çarpıklık-basıklık değerleri üzerinden incelendi. Gruplara ait verilerinin normal dağılım sergilemediği görülerek, grupların karşılaştırılması için non-parametrik test yöntemlerinden biri olan Kruskal Wallis-H testi kullanıldı. Gruplar arasında anlamlı fark çıkması durumunda, farkın hangi grutan kaynaklandığını bulmak için Bonferroni düzeltmeli Mann-Whitney-U testinin gerçekleştirilmesi öngörülmüştür. Bütün istatistiksel yöntemler için yanılma düzeyi $(\alpha) 0,05$ olarak kabul edildi. 
Ayan, V., Yüksek, S., Gür, F., Kural, B., \& Demircan, Y. (2021). Puberte Dönemindeki K1z Mücadele Sporcularının Antropometrik Ölçümlerinin ve Somatotip Yapılarının İncelenmesi. Ulusal Spor Bilimleri Dergisi, $5(2), 138-145$.

\section{BULGULAR}

Araştırmaya katılan sporcuların branşlarına göre antropometrik ve somatotip ölçüm değerlerinin ortlama değerleri ve karşılaştırma sonuçları tablo 1'de gösterilmiştir.

Tablo 1. Kız sporcuların branşa göre antropometrik ve somatotip ölçüm değerlerinin karşılaştırılması

\begin{tabular}{|c|c|c|c|c|}
\hline Değişkenler & $\begin{array}{c}\text { Taekwondo } \\
\text { (N: 16) } \\
\mathrm{X} \pm \mathrm{SS}\end{array}$ & $\begin{array}{c}\text { Judo } \\
\text { (N: 16) } \\
\text { X } \pm \text { SS }\end{array}$ & $\begin{array}{c}\text { Karate } \\
(\mathbf{N}: 9) \\
X \pm \mathbf{S S}\end{array}$ & $\mathbf{p}^{*}$ \\
\hline Yaş (yıl) & $12.94 \pm 1.23$ & $12.75 \pm 1.48$ & $12.00 \pm 1.73$ & 0.493 \\
\hline Vücut Ağırlığg (kg) & $37.43 \pm 11.04$ & $41.35 \pm 15.47$ & $36.86 \pm 9.97$ & 0.763 \\
\hline Boy Uzunluğu (cm) & $141.75 \pm 9.96$ & $146.25 \pm 7.85$ & $139.55 \pm 9.50$ & 0.182 \\
\hline Triceps Dkk (mm) & $12.15 \pm 4.16$ & $9.63 \pm 4.04$ & $13.46 \pm 3.94$ & 0.681 \\
\hline Scapula Dkk (mm) & $9.52 \pm 4.34$ & $8.90 \pm 7.50$ & $10.51 \pm 4.62$ & 0.094 \\
\hline Iliac Dkk (mm) & $10.06 \pm 5.64$ & $8.36 \pm 7.29$ & $10.73 \pm 5.92$ & 0.104 \\
\hline Calf Dkk (mm) & $14.76 \pm 4.62$ & $13.11 \pm 6.88$ & $14.00 \pm 6.67$ & 0.311 \\
\hline Biceps Çevre (cm) & $21.32 \pm 3.00$ & $22.77 \pm 3.94$ & $21.38 \pm 2.57$ & 0.536 \\
\hline Calf Çevre (cm) & $30.00 \pm 3.97$ & $30.10 \pm 4.52$ & $29.13 \pm 3.19$ & 0.892 \\
\hline Dirsek Genişlik (cm) & $5.64 \pm .43$ & $5.71 \pm .47$ & $5.37 \pm .32$ & 0.145 \\
\hline Diz Genişlik (cm) & $8.61 \pm .70$ & $8.78 \pm .79$ & $8.37 \pm .48$ & 0.375 \\
\hline VKİ $\left(\mathrm{kg} / \mathrm{m}^{2}\right)$ & $18.23 \pm 3.24$ & $18.96 \pm 5.26$ & $18.71 \pm 3.77$ & 0.761 \\
\hline Endomorf & $3.75 \pm 1.39$ & $3.06 \pm 1.61$ & $4.11 \pm 1.36$ & 0.062 \\
\hline Mezomorf & $4.37 \pm .95$ & $4.31 \pm 1.62$ & $4.11 \pm 1.36$ & 0.781 \\
\hline Ektomorf & $2.87 \pm 1.40$ & $3.00 \pm 1.63$ & $2.77 \pm 1.20$ & 0.844 \\
\hline
\end{tabular}

* Kruskal Wallis -H Testi anlamlılık değeri

Taekwondo, judo ve karate branşındaki sporcuların antropometrik ve somatotip ölçüm değerlerinin branşa göre karşılaştırılması sonucunda istatistiksel açıdan anlamlı fark görülmemiştir ( $\mathrm{p}>0.05$, Tablo 1).

Tablo 2'de araştırmaya katılan kız sporcularının somatokart üzerindeki X ve Y istatistiki değerleri verilmiştir.

Tablo 2. Kız sporcularının somatokart $\mathrm{X}$ ve $\mathrm{Y}$ istatistiki değerleri

\begin{tabular}{ccccc}
\hline Değişkenler & $\begin{array}{c}\text { Taekwondo } \\
(\mathrm{n}: 16) \\
\text { Ort. } \pm \text { SS }\end{array}$ & $\begin{array}{c}\text { Judo } \\
(\mathrm{n}: 16) \\
\text { Ort. } \pm \text { SS }\end{array}$ & $\begin{array}{c}\text { Karate } \\
(\mathrm{n}: \text { 9) } \\
\text { Ort. } \pm \text { SS }\end{array}$ & $\mathrm{P}^{*}$ \\
\hline $\mathrm{X}$ & $-0.89 \pm 2.60$ & $0.17 \pm 3.19$ & $-1.56 \pm 2.31$ & 0.190 \\
\hline $\mathrm{Y}$ & $1.99 \pm 1.98$ & $2.38 \pm 3.03$ & $1.38 \pm 2.54$ & 0.629 \\
\hline
\end{tabular}

* Kruskal Wallis -H Testi anlamlılık değeri

Kı sporculara ait somatotip değer ve ortalamaların somatokart üzerindeki dağglımları şekil 1 ve 2'de görülmektedir. Gruplar arasında yapılan karşılaştırma sonucunda istatistiksel açıdan anlamlı fark görülmemiştir. 


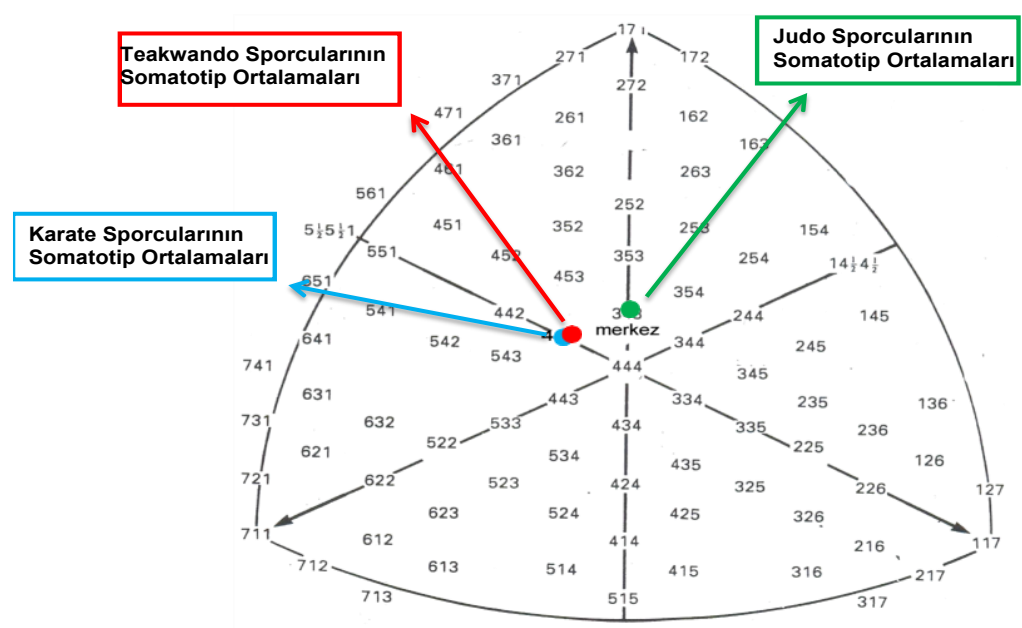

Şekil 1. Kız sporculara ait somatotip değer ortalamalarının somatokart üzerindeki dağılımları

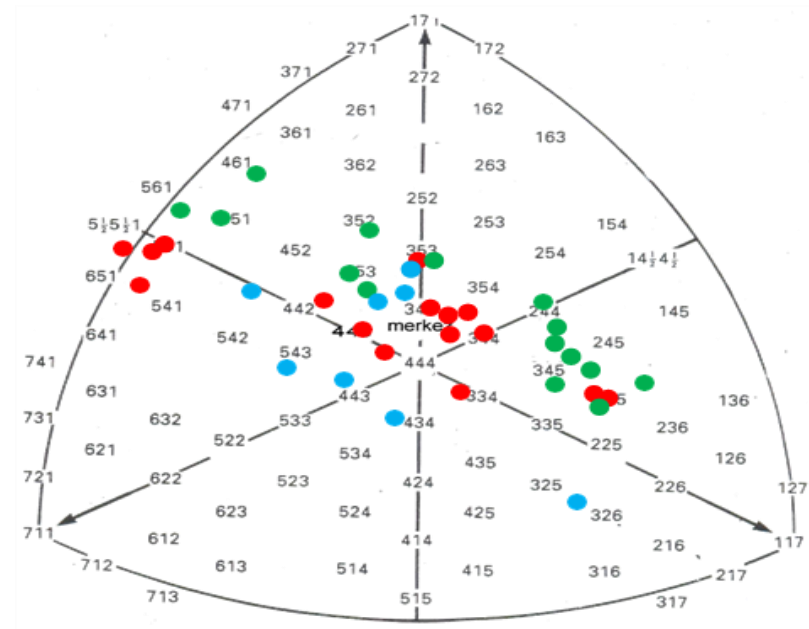

Şekil 2. Kız sporculara ait somatotip değerlerinin somatokart üzerindeki dağılımları

\section{TARTIŞMA VE SONUÇ}

$\mathrm{Bu}$ araştırma puberte dönemindeki kız mücadele sporcularının antropometrik özellikleri ile somatotip yapılarını belirlemek ve farklı branşlarda bu özellikleri karşılaştırmak amacı ile gerçekleştirilmiştir. Araştırma kapsamında mücadele sporları arasında yer alan taekwondo, judo ve karate branşlarını lisanslı olarak uygulayan kız sporcuların antropometrik özellikleri ve somatotip yapıları belirlenmiştir.

Araştırmada kız taekwondo sporcuların somatotip ortalama değerleri 4-4-3 (mezomorf endomorf) olarak bulunmuştur. Müniroğlu, Ghorbanzadeh, Akalan ve Şahin (2011) yapmış oldukları araştırmada Türk Taekwondo Milli takımında yarışan kadın sporcuların (yaş ort. $18.76 \pm 1.52$ y1l, $22.37 \pm 4.73$ y1l) somatotip değerlerini 2-5-3 (ektomorfik mezomorf) olarak bulmuşlardır. Burdukiewicz vd., (2016) yapmış oldukları kadın mücadele sporcularının (yaş ort. $21.2 \pm 1.81$ yıl) morfolojisi başlıklı çalışmalarında ise taekwondo sporcularının 
Ayan, V., Yüksek, S., Gür, F., Kural, B., \& Demircan, Y. (2021). Puberte Dönemindeki Kız Mücadele Sporcularının Antropometrik Ölçümlerinin ve Somatotip Yapılarının İncelenmesi. Ulusal Spor Bilimleri Dergisi, $5(2), 138-145$.

somatotiplerini 3,1-3,8-2,7 (endomorfik mezomorf) olarak bulmuşlardır. Ölmez, Vedat, Yüksek, Öztaş ve Civil (2018) 11-13 yaş erkek taekwondo sporcularının somatotip yapılarını 4-5-3 (endomorfik mezomorf) olarak bulmuşlardır.

Taekwondo sporcularıyla ilgili literatür incelendiğinde yapılan çalışmalarda Taekwondo sporcularının somatotip yapılarının ektomorfik-mezomorf ve endomorfik-mezomorf değerleri arasında olduğu ve mezomorf yapının baskın özellik olduğu görülmektedir. Araştırmamızda elde edilen sonuçların literatür çalışmalardan elde edilen sonuçlarla paralellik gösterdiği, puberte döneminde de kız sporcuların mezomorfik yapının özelliklerine sahip olduğu görülmektedir. Bununla birlikte puberte dönemindeki kız sporcularda görülen endomorfik yapının hormonal değişimler ve beslenme alışkanlıkları ile ilişkili olabileceği düşünülmektedir (Olds, 2009).

Araştırmadaki kız judo sporcuların somatotip ortalama değerleri 3-4-3 (dengeli mezomorf)

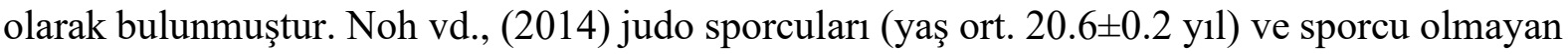

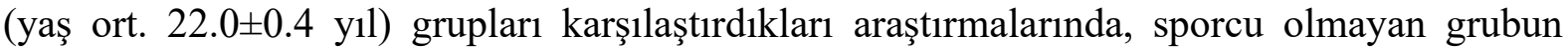
somatotip ortalamalarını 3,0-3,4-2,5 ve judocuların somatotip ortalamalarını 2,3-5,0-1,1 olarak

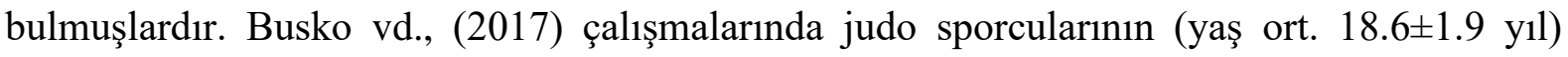
somatotip ortalamalarını 3,2-5,8-1,8 (endomorfik mezomorf) olarak bulmuşlardır. Burdukiewicz vd., (2016) ise yapmış oldukları kız mücadele sporcularının morfolojisi başlıklı çalışmalarında judo sporcularının (yaş ort. $21.2 \pm 1.81$ yıl) somatotiplerini 3,5-5,1-1,6 (endomorfik mezomorf) olarak bulmuşlardır. Judo sporcularıyla ilgili literatür incelendiğinde yapılan çalışmalarda judo sporcularının endomorfik mezomorf somatotip yapıya sahip oldukları ve mezomorfik yapının baskın olduğu görülmektedir. Araştırmada judo sporcularının somatotip yapılarından elde edilen sonuçların literatür sonuçları ile benzerlik gösterdiği ve puberte dönemi kız sporcularının da mezomorfik yapıyı koruduklarını göstermektedir.

Araştırmada kız karate sporcuların somatotip ortalama değerleri 4-4-3 (mezomorf endomorf) olarak bulunmuştur. Pieter ve Bercades (2009) ulusal elit mücadele sporcularının somatotip yapılarını inceledikleri çalışmalarında kız elit karate sporcularının (yaş ort. $20.33 \pm 2.58$ yıl) somatotip ortalamalarını 3,0-3,6-2,3 olarak bulmuşlardır. Burdukiewicz vd., (2016) yapmış oldukları kadın mücadele sporcularının (yaş ort. $21.2 \pm 1.81$ yıl) morfolojisi başlıklı çalışmalarında, karate sporcularının somatotip ortalamalarını 3,5-4,0-2,5 olarak tespit etmişlerdir. Katic vd., (2005) ise elit karate sporcularının (yaş aralığı 18 ila 29 yıl) baskın olarak mezomorfik bir yapıya sahip olduklarını rapor etmiştir. Karate sporcularıyla ilgili literatür incelendiğinde yapılan çalışmalarda karate sporcularının endomorfik mezomorf ve mezomorfik somatotip yapıya sahip oldukları görülmektedir. Bu sonuçlar puberte dönemindeki kız sporcuların göstermiş olduğu mezomorf-endomorf yapının literatürle benzer olduğunu ve branşa özgü yapının bu dönemde sağlanabildiğini göstermektedir.

Araştırmada kız sporcuların antropometrik özellikleri deri kıvrımı kalınlığı (triceps, scapular, illiac ve calf), genişlik (dirsek, diz) ve çevre (biceps ve calf) ölçümleri açısından branşlar arasında istatiksel olarak anlamlı bir fark görülmemiştir ( $p>0.05)$. Bununla birlikte elde edilen bulgular incelendiğinde, kız sporcuların somatotip ortalama değerleri taekwondo branşında (44-3) (mezomorf endomorf), judo branşında (3-4-3) (dengeli mezomorf) ve karate branşında (4- 
4-3) (mezomorf endomorf) olarak bulunmuş ve kız sporcuların somatotip yapıları branşa göre karşılaştırıldığında gruplar arasında istatiksel olarak anlamlı bir fark görülmemiştir ( $>00.05)$.

Araştırma verileri literatürle birlikte incelendiğinde hem puberte döneminde hem de yetişkin dönemde mücadele sporcuları açısından baskın somatotip yapının mezomorfik yapı olduğu görülmektedir. Bununla birlikte puberte döneminde mezomorfik yapıya eşlik eden endomorfik yapının yetişkinlik dönemine geçildikçe elit sporcularda yerini ektomorfik yapıya bıraktığ anlaşılmaktadır. Bu durumun mücadele sporlarının doğasında olan kuvvet ve hız gibi motor özelliklerinin daha iyi sergilenebilmesi için gerekli olduğu düşünülmektedir.

Sporcuların somatotip yapıları spora yönlendirmede ve performanslarını sergilemede oldukça önemlidir. Mücadele sporcularının uyguladıkları dövüş yöntemleri ve kullandıkları teknikler nedeniyle antropometrik özellikleri ve somatotip yapılarında belirli farklılıklar vardır. $\mathrm{Bu}$ farklılıkların belirlenmesi sporculara ve antrenörlere vücut bölümlerini en iyi şekilde kullanmak için yardımcı olabilecek bilgiler sağlayabilir. Sonuç olarak; mücadele sporcularının somatotip yapılarında baskın özelliğin mezomorfik yapıdan yana olduğu söylenebilir. Bununla birlikte somatotip yapı ve özellikleri sporcuların içinde bulunduğu gelişim dönemlerine göre farklılıklar gösterebilir.

Yayın Etiği: $\mathrm{Bu}$ çalışmanın hazırlanma ve yazım sürecinde "Yükseköğretim Kurumları Bilimsel Araştırma ve Yayın Etiği Yönergesi” kapsamında bilimsel, etik ve alıntı kurallarına uyulmuş olup; toplanan veriler üzerinde herhangi bir tahrifat yapılmamış ve bu çalışma herhangi başka bir akademik yayın ortamına değerlendirme için gönderilmemiştir.

Çıkar Çatışması: Yazarlar arasında herhangi bir çıkar çatışması yoktur.

Araştırmacıların Katkı Oranı Beyanı: Yazarların tamamı araştırmanın tasarım, ölçüm, analiz ve yazım süreçlerine ortak katkıda bulunmuştur.

\section{KAYNAKLAR}

Ackland, T. R., Lohman, T. G., Sundgot-Borgen, J., Maughan, R. J., Meyer, N. L., Stewart, A. D. \& Müller, W. (2012). Current status of body composition assessment in sport. Sports medicine, 42(3), 227-249. https://doi.org/10.2165/11597140-000000000-00000

Burdukiewicz, A., Pietraszewska, J., Andrzejewska, J. \& Stachon, A. (2016). Morphological optimization of female combat sports athletes as seen by the anthropologists. Anthropological Review, 79(2), 201. https://doi.org/10.1515/anre-2016-0015

Buśko, K., Pastuszak, A. \& Kalka, E. (2017). Body composition and somatotype of judo athletes and untrained male students as a reference group for comparison in sport. Biomedical Human Kinetics, 9, 7-13. https://doi.org/10.1515/bhk-2017-0002 
Ayan, V., Yüksek, S., Gür, F., Kural, B., \& Demircan, Y. (2021). Puberte Dönemindeki Kız Mücadele Sporcularının Antropometrik Ölçümlerinin ve Somatotip Yapılarının İncelenmesi. Ulusal Spor Bilimleri Dergisi, $5(2), 138-145$.

Carter, J. L. \& Heath, B. H. (1990). Somatotyping: Development and applications (C. 5). Cambridge university press.

Gürbüz, S., \& Şahin, F. (2014). Sosyal bilimlerde araştırma yöntemleri. Ankara: Seçkin Yayıncılık, 271.

Habelt, S., Hasler, C. C., Steinbrück, K. \& Majewski, M. (2011). Sport injuries in adolescents. Orthopedic Reviews, 3(2), e18. https://doi.org/10.4081/or.2011.e18

Hume, P. A. \& Stewart, A. D. (2018). Physique assessment in youth sports for talent identification and development. İçinde Best Practice Protocols for Physique Assessment in Sport (ss. 3-10). Springer. https://doi.org/10.1007/978-981-10-5418-1_1

Katić, R., Blažević, S., Krstulović, S. \& Mulić, R. (2005). Morphological structures of elite karateka and their impact on technical and fighting efficiency. Collegium Antropologicum, 29(1), 79-84.

Marfell-Jones, M., Olds, T., Stewart, A. \& Carter, L. (2006). ISAK Accreditation Handbook. https://researchportal.vub.be/en/publications/isak-accreditation-handbook.

Maughan, R. J. (2009). The Olympic Textbook of Science in Sport. Oxford: John Wiley \& Sons.

Müniroğlu, S., Ghorbanzadeh, B., Akalan, C. \& Şahin, M. (2011). Türk taekwondo milli takımının somatotip özelliklerinin incelenmesi. Sport Sciences, 6(3), 169-177.

Noh, J.-W., Kim, J.-H. \& Kim, J. (2014). Somatotype analysis of elite judo athletes compared with nonathletes for health science research. Toxicology and Environmental Health Sciences, 6(2), 99-105. https://doi.org/10.1007/s13530-014-0193-X

Olds, T. (2009). Body composition and sports performance. In The Olympic Textbook of Science in Sports; Maughan, R., Ed, 131-145. Oxford: John Wiley \& Sons.

Ölmez, C., Vedat, A., Yüksek, S., Öztaş, M. \& Civil, T. (2018). 11-13 yaş erkek taekwondo sporcularının somatotip yapıları ve performans özellikleri arasındaki ilişkinin incelenmesi. Ulusal Spor Bilimleri Dergisi, 3(1), 1-13. https://doi.org/10.30769/usbd.534672

Pieter, W. \& Bercades, L. T. (2009). Somatotypes of national elite combative sport athletes. Brazilian Journal of Biomotricity, 3(1), 21-30.

Roemmich, J. N., Richmond, E. J. \& Rogol, A. D. (2001). Consequences of sport training during puberty. Journal of Endocrinological Investigation, 24(9), 708-715. https://doi.org/10.1007/BF03343915

Silva, V. S. \& Vieira, M. F. S. (2020). International Society for the Advancement of Kinanthropometry (ISAK) Global: International accreditation scheme of the competent anthropometrist. Revista Brasileira de Cineantropometria \& Desempenho Humano, 22,22:e70517. https://doi.org/10.1590/1980$0037.2020 \mathrm{v} 22 \mathrm{e} 70517$

Susman, E. J. \& Rogol, A. (2004). Puberty and psychological development. İçinde Handbook of adolescent psychology, 2nd ed. (ss. 15-44). John Wiley \& Sons Inc.Handbook of adolescent psychology, 2nd ed. Hoboken, NJ, US: John Wiley \& Sons Inc.

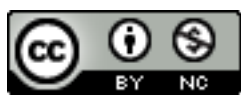

Bu eser Creative Commons Atıf-Gayri Ticari 4.0 Uluslararası Lisansı ile lisanslanmıştır. 